\title{
LAS CORRIENTES POLÍTICAS DEL PARTIDO DE LA REVOLUCIÓN DEMOCRÁTICA EN EL DISTRITO FEDERAL (1997-2012)
}

Carlos Cruz Arzate

\section{INTRODUCGIÓN}

La Ciudad de México es la capital del país y una de las ciudades más grandes en el mundo. Es ahí donde residen los tres Poderes de la Unión y es la entidad federativa que aporta el mayor porcentaje del Producto Interno Bruto (PIB) del país con 17.1\%. ${ }^{1}$ Además, tiene la demarcación con mayor ingreso per cápita nacional (delegación Benito Juárez) de aproximadamente 28000 dólares anuales en promedio ${ }^{2}$ y el Índice de Desarrollo Humano más alto. ${ }^{3}$ Sin embargo, también existen zonas con altos niveles de marginación en delegaciones como Tlalpan, Iztacalco, Álvaro Obregón y Gustavo A. Madero por mencionar algunas. ${ }^{4}$

Desde 1997 el Partido de la Revolución Democrática (PRD) ha ganado en cuatro ocasiones la Jefatura de Gobierno de la Ciudad

${ }^{1}$ Secretaría de Desarrollo Económico. Reporte Económico de la Ciudad de México, enero 2016, http://reporteeconomico.sedecodf.gob.mx/index.php/site/ main/14

${ }^{2}$ Cámara de Diputados, Perfil socioeconómico del Distrito Federal, junio de 2009, http://www.cefp.gob.mx/intr/edocumentos/pdf/cefp/2009/cefp0372009. pdf

${ }^{3}$ Programa de Naciones Unidas para el Desarrollo, Índice de Desarrollo Humano Municipal en México, 2004, http://www.undp.org.mx/desarrollohumano/ eventos/images/CuadernilloIDHMM.pdf

${ }^{4}$ Atlas Socioeconómico y de Marginación para el D. F. de la Coordinación de Planeación del Desarrollo Territorial, http://www.siege.df.gob.mx/copladet/index.html 
de México. Antes de ese año, el presidente en turno era quien designaba al otrora Regente del Departamento del Distrito Federal. El primer periodo, 1997-2000, fue único en su momento por dos razones: 1) fue la primera ocasión en que la ciudadanía eligió al jefe de gobierno por sufragio universal; y 2) éste nombró a los encargados de cada una de las delegaciones. Posteriormente, éstos fueron elegidos por la ciudadanía para una duración de tres años en el cargo. Desde entonces han transcurrido cuatro elecciones para jefe de gobierno y para senadores, así como seis elecciones para jefes delegacionales, diputados locales y diputados federales. En cada proceso electoral se han contendido por alrededor de cien puestos de representación popular que hay en la ciudad. Hasta el año 2015, la mayoría de éstos los obtuvo el PRD y el Partido Acción Nacional (PAN) como segunda fuerza política.

Ante esta situación la pregunta que guía el presente artículo es analizar de qué manera estaba organizado este partido político en la capital del país en la que fue la primera fuerza política hasta 2015. La hipótesis es que efectivamente hay una élite partidista que se organiza en corrientes políticas o facciones ${ }^{5}$ las cuales funcionan como un mecanismo (además de utilizar el patronazgo ${ }^{6}$ ) necesario para que los individuos que la integran puedan hacer carrera política. Aun cuando se considera que el PRD es un partido de izquierda, éste se comporta como cualquier otra organización partidaria: vertical y mediante grupos políticos.

${ }^{5}$ A partir de ahora, estos conceptos se utilizarán de forma indistinta, aun cuando líneas más adelante se definirá el concepto específico de facción que entenderemos en el presente artículo. El término corriente política es la que establece el PRD en sus estatutos.

${ }^{6}$ Susan Stokes define patronazgo como sinónimo de clientelismo, el cual se define como el intercambio que se genera cuando algunos ciudadanos otorgan apoyo político a cambio de obtener un trabajo en el sector público. Susan C. Stokes, "Political Clientelism", en Robert E. Goodin, Carles Boix, Susan C. Stokes, The Oxford Handbook of Comparative Politics, Oxford, Oxford University Press, 2007, p. 606. En este caso, no utilizaré patronazgo como sinónimo de clientelismo, sino como un mecanismo distinto a éste, el cual no únicamente denota el intercambio apoyo-empleo en sector público, sino que también describe el intercambio de apoyo-cesión de contratos entre partido político o gobierno con particulares. 
Desde 1997, integrantes y militantes del PRD han mantenido muchos puestos de representación popular en el la Ciudad de México. Esto ha provocado una lucha dentro del partido, entre las diferentes corrientes, para obtener la mayor cantidad de candidaturas a puestos de representación y cargos públicos. Lo anterior implicó una primera disputa por los distintos cargos partidistas, en los cuales se decide el método de elección de los candidatos a elección popular. Entre más cantidad de miembros tengan las facciones en los órganos partidistas, mayor será la posibilidad de influir en el método de elección a los candidatos de representación.

Este comportamiento partidista no debería sorprender. Robert Michels, sociólogo alemán y quien hizo un análisis de los partidos políticos, afirmó que éstos tienden hacia una burocratización y a la constitución de una dirigencia para hacer eficientes sus labores de organización. Esto provoca que éstas tiendan a mantener un control perenne sobre los recursos del partido. Posteriormente, Angelo Panebianco, politólogo italiano, analizó algunas de las características más importantes de los partidos políticos, entre las que se encuentra la constitución de la coalición dominante. La coalición de un partido político es la élite dirigente del mismo. Cada uno de los miembros que la conforman controla ciertas zonas de incertidumbre, ${ }^{7}$ las cuales sirven para obtener ventajas de los actores de una misma élite sobre otros. Esta coalición podría ser, en palabras de Robert Michels, una estructura compleja, la cual "se mantiene esencialmente antidemocrática en su naturaleza, [aunque] en ciertos periodos de su vida política se encuentra obligada, sea como fuere, a hacer profesión democrática, o al menos a adoptar la máscara democrática" ${ }^{8}$

Bajo estos enfoques se puede catalogar que cualquier organización partidista, aun cuando se encuentre en el espectro ideológico de izquierda con un discurso incluyente y equitativo, habita una élite con el interés de mantener el control sobre los recursos que hay en el mismo.

${ }^{7}$ Panebianco define estas zonas como factores cuyo control permite a ciertos actores desequilibrar en su favor los juegos de poder. Angelo Panebianco, Modelos de partido, tr. Mario Trinidad, Madrid, Alianza, 1990, p. 83.

${ }^{8}$ Robert Michels, Los partidos políticos. Un estudio sociológico de las tendencias oligárquicas de la democracia moderna, Buenos Aires, Amorrortu, 1969, p. 49. 
EL PRD: PROGESO DE FORMACIÓN DE UNA COALICIÓN DOMINANTE Y EL PAPEL DE SUS CORRIENTES POLÍTICAS

Diversas investigaciones han descrito cómo nació el PRD y cuáles han sido las consecuencias de su origen multipartidista. En ellas explican el proceso de separación de la Corriente Democrática del Partido Revolucionario Institucional (PRI), liderada principalmente por Cuauhtémoc Cárdenas Solórzano y Porfirio Muñoz Ledo, entre otros; cómo diversos partidos políticos (algunos con inexistente participación institucional dentro del sistema de partidos, pero con presencia en algunos estados del país) y movimientos sociales se aglutinaron en torno a Cárdenas Solórzano, quien fungió como candidato a la presidencia por el Frente Democrático Nacional (FDN) en 1988; y cómo, después de la elección, se discutió, se conformó y se formalizó el Partido de la Revolución Democrática. ${ }^{9}$

Posteriormente a la conformación del partido, se estableció la coalición dominante en el ámbito nacional y en los estados. La primera se conformó con miembros de las distintas organizaciones que formaron el PRD, pero principalmente de la Corriente Democrática. Posteriormente, los actores del PRD se organizaron en lo que se conoce como corrientes de opinión, las cuales están reconocidas en sus estatutos. ${ }^{10}$ En dichas corrientes, algunos militantes se reagruparon y no necesariamente con sus grupos de origen, sino

${ }^{9}$ Para saber más sobre este tema, véase: 1) Reynaldo Yunuen Ortega Ortiz, “El proceso de democratización en México, 1968-2002”, en Walther L. Bernecker (comp.), Transición democrática y anomia social en perspectiva comparada, México, El Colegio de México, 2004; 2) Reynaldo Yunuen Ortega Ortiz, "El Partido de la Revolución Democrática y los movimientos sociales”, en Ilán Bizberg y Francisco Zapata (coords.), Los grandes problemas de México, vol. vi: Movimientos sociales, México, El Colegio de México, 2010; 3) Kathleen Bruhn, Taking on Goliath: The Emergence of a New Left Party and the Struggle for Democracy in Mexico, Filadelfia, Pennsylvania Univsersity Press, 1997; 4) Francisco Reveles Vázquez (coord.), Partido de la Revolución Democrática. Los signos de la institucionalización, México, unam-Gernika, 2004.

${ }^{10}$ De manera formal, esto se encuentra en los primeros estatutos del partido donde se reconoce la existencia de corrientes. Esto se discutió y ratificó en julio de 1990 en el I Foro Nacional de Estatutos. Jean-François Prud'homme, "El PRD: su vida interna y sus elecciones estratégicas", CIDE, Documento de trabajo de la División de Estudios Políticos, núm. 39, 1996, p. 14. La Jornada, 24 de junio de 1990. 
con distintos miembros del partido. Por lo tanto, la coalición también se reorganizó. Esta dinámica se observa empíricamente en la integración de las dirigencias partidistas, ya que ahí los militantes ocupan espacios representando a sus respectivas facciones. En el caso del PRD se presenta en la conformación de los comités ejecutivos nacionales, estatales y municipales. Es decir, las corrientes de opinión o facciones son partes fundamentales para la formación de la coalición. ${ }^{11}$

Para entender el comportamiento del PRD es necesario retomar algunas ideas sobre la evolución de los partidos políticos y delimitar el concepto de corriente política que se ha usado de manera indistinta con facción hasta el momento. Para ello, Panebianco usa dos instrumentos analíticos: la historia organizativa del partido político y las relaciones que establece éste con su entorno, las cuales siempre están cambiando. El primero se refiere a cómo nació la organización y cómo sus características de origen pueden influir en ella, aun en un periodo largo de tiempo. Para el segundo instrumento, Panebianco usa el concepto institucionalización para entender cómo la organización se ha consolidado. "La institucionalización es el proceso mediante el cual la organización incorpora los valores y fines de los fundadores del partido." ${ }^{12}$ Cuando un partido político se institucionaliza, "la organización pierde poco a poco el carácter de instrumento valorado no por sí mismo sino sólo en función de los fines organizativos: adquiere un valor en sí mismo, los fines se incorporan a la organización y se convierten en inseparables y a menudo indistinguibles de ella". ${ }^{13}$ Lo característico de la institucionalización es que todos los miembros de la organización tienden a coincidir con los fines de la misma. Sin embargo, esta coincidencia de fines de la organización se establece, según Panebianco, por dos razones: 1) el desarrollo de intereses en el mantenimiento de la organización por parte de los dirigentes y 2) desarrollo y difusión de lealtades organizativas.

11 Para un mejor estudio de este tema, se puede ver Francisco Reveles Vázquez, "Fundación e institucionalización del PRD: liderazgos, fracciones y confrontaciones” en Francisco Reveles Vázquez, op. cit., pp. 11-71.

12 Angelo Panebianco, op. cit., p. 115.

${ }^{13}$ Loc. cit. 
En este proceso de institucionalización, los fundadores o creadores de la organización poseen intereses que pretenden mantener. De esta manera, aquéllos fraguan lealtades con miembros de la organización para sostenerlos, pero estos intereses particulares son tantos como liderazgos haya dentro de la organización. Sin embargo, para que unos reconozcan a los otros (y viceversa) se debe mantener un equilibrio interno entre los distintos intereses que forman la coalición dominante.

Para mantener este equilibrio se reconocen las facciones políticas, las cuales se establecen para negociar y pactar entre ellas. Éstas son producto natural de cualquier organización, ya que:

Es obvio que un número tan gigantesco de personas pertenecientes a una organización unitaria no puede realizar ninguna tarea práctica con el sistema del debate directo. Las asambleas deliberativas regulares de un millar de miembros encuentran las dificultades más graves en lo que a espacio y distancia se refiere [...] Hay, sin embargo, otras razones de carácter técnico y administrativo que hacen imposible el gobierno propio y directo de grandes grupos [por lo tanto] en el partido democrático moderno es imposible que la colectividad emprenda la solución directa de todas las controversias que puedan surgir [...] De allí la necesidad de delegación, de un sistema donde haya delegados que representen a la masa y lleven a la práctica su voluntad. ${ }^{14}$

Lo anterior no sólo obedece a la masa, sino también a los militantes de un partido político, quienes necesitan ser representados en los órganos de decisión del mismo.

La representación de los militantes dentro del partido ha provocado que esta tarea sea cada vez más complicada, por lo que: "se hizo cada vez más esencial alguna capacidad o aptitud individual: ciertos dones oratorios, y una cantidad considerable de conocimiento objetivo. De esta manera resultó imposible confiar en una designación a ciegas, en la fortuna del orden alfabético, o en el orden de prioridad, en la elección de una delegación cuyos miembros debían poseer ciertas aptitudes personales peculiares para

${ }^{14}$ Robert Michels, op. cit., p. 72. 
desempeñar su misión ventajosamente" ${ }^{15}$ Esto fue una de las causas por las que aparecieron las facciones políticas. Esta idea es sostenida por William N. Chambers, quien menciona que éstas se crearon originalmente para formar, posteriormente, los partidos políticos.

Teóricamente, las facciones representan un tema que puede tratarse desde distintas aristas: su nacimiento, su composición, su influencia en el partido, sus integrantes y líderes, sus actividades, la cantidad de representantes de cada una de ellas en los espacios de representación partidista y cargos públicos, entre otras. A lo largo del tiempo, las connotaciones hacia las facciones han sido siempre en sentido negativo. Aun cuando no haya este tipo de calificaciones negativas, las facciones suelen ser vistas como insignificantes o como temporales, por lo que se les da sólo una importancia momentánea. Además, está la idea de que las facciones sólo se presentan en contextos específicos, cuando éstas sirven para instalar mayorías o minorías sobre un tema específico para luego desaparecer. ${ }^{16}$

Dennis C. Beller y Frank P. Belloni definen facción como "un grupo relativamente organizado que existe dentro de un contexto de otro grupo, el cual, como facción política, compite con otros rivales por obtener ventajas de poder dentro del gran grupo del que forma parte". ${ }^{17}$ William N. Chambers las define como "una porción de la élite política nacional, de la legislatura o del electorado, con seguidores que están con actividades paralelas o coordinadas, las cuales están en conflicto con otra porción o porciones de la élite. Es decir, las diferencias son críticas". ${ }^{18}$ Las facciones son de difícil identificación porque no se dejan ver con claridad, ya que únicamente se reúnen cuando hay elecciones o temas en la agenda pública que provocan su aparición. Por lo tanto, el autor

15 Ibid., p. 74.

${ }^{16}$ Frank P. Belloni y Dennis C. Beller, "The Study of Party Factions as Competitive Political Organizations”, The Western Political Quaterly (University of Utah), vol. 9, núm. 4, 1996, p. 533.

${ }^{17}$ Frank P. Belloni y Dennis C. Beller, "Party and Faction: Modes of Political Competition", en Dennis C. Beller y Frank P. Belloni, Faction Politics: Political Parties and Factionalism in Comparative Perspective, Oxford, ABC-Clio, 1978, p. 419.

${ }^{18}$ Frank P. Belloni y Dennis C. Beller, art. cit., p. 535. 
argumenta que las facciones son "semi-visibles", irregulares e inestables. Para Belloni y Beller, Chambers caracteriza a la facción por tener falta de claridad, orden, procedimientos estables, así como carecía de ideologías, héroes y símbolos que las hagan distintas y durables. ${ }^{19}$

Ralph W. Nicholas define a la facción como "líder-seguidores", donde las actividades están muy bien definidas: los seguidores apoyan al líder en el parlamento y en luchas intrapartidistas; en cambio, el líder provee posiciones, dinero u otras necesidades para mejorar el nivel de vida de los primeros. Las ataduras de las facciones son personales, entre el líder y el seguidor, y están basadas en un cálculo personal de mutuo interés. Menciona que las facciones tienen una construcción mejor definida que un grupo de individuos que únicamente se junta y se coordina en un conflicto político, pero afirma que están menos desarrolladas que un partido político. Belloni y Beller consideran que este autor invita a estudiar a las facciones por lo que hacen o por lo que son y consideran que su análisis destaca más por enfatizar los aspectos organizacionales que por el conflicto entre aquéllas. ${ }^{20}$

Para Richard Rose las facciones son grupos de individuos representados en el parlamento, quienes tratan de impulsar una serie de políticas mediante una actividad política organizada. Las facciones se distinguen de otros grupos por el tipo de miembros que las componen, ya que éstos son del parlamento y no de la sociedad civil. Bajo estos términos, las facciones están organizadas, como cuerpo único, con cierta disciplina y cohesión. ${ }^{21}$

Rose reconoce que las facciones necesitan de un liderazgo, el cual les proporciona dirección, estatus y, tácticamente, les provee remuneración política como representante de la facción ante la negociación con otras. Además, la ideología juega un papel muy importante, ya que representa una serie de valores e intereses

19 Loc. cit.

20 Ibid., p. 536.

21 Richard Rose, "Parties, Factions and Tendencies in Britain", Political Studies, Washington, D. C., American Political Science Association, vol. 12, núm. 1, 1964 , p. 37. 
compartidos para que los miembros de la misma realicen actividades coherentes y coordinadas.

Contrario a las facciones están las tendencias, las cuales son actitudes y no un grupo estable de miembros del partido. Es decir, son actitudes expresadas en el parlamento sobre ciertos problemas, las cuales están sujetas a una ideología política coherente. Las tendencias no son grupos estables a menos que los miembros que expresen estas actitudes decidan convertirse en una facción.

Valdimer Orlando Key afirma que las facciones dependen de líderes individuales o "notables" de un partido político, quienes, la mayoría de las veces, forman facciones para juntar seguidores que los apoyen en candidaturas para ocupar cargos públicos. Este autor tiene más interés por las actividades de las facciones que por lo que éstas son. Mediante esta definición se puede observar cómo es la competencia entre facciones y cómo colocan candidatos para ocupar cargos públicos. Key agrega que la política de facciones conlleva a gobiernos disfuncionales debido a que en la administración pública laboran diferentes facciones que no trabajan bajo una misma dirección.

Joy Langston conceptualiza las facciones políticas como: "grupos cooperadores en el sentido de que sus miembros trabajan juntos para alcanzar metas comunes y propias. De esta manera, observamos la clásica tensión de los arreglos colectivos: si todos los individuos procuran sus fines personales y no cooperan, entonces los propósitos del grupo se verán amenazados y cada actor terminará peor que si hubiera cooperado". ${ }^{22}$

Ella observa a las facciones desde el punto de vista de los individuos y de la cooperación entre ellos, para que cada uno alcance sus propias metas. Sin embargo, no limita las facciones como vehículo para redistribuir bienes y cargos, sino como medios para acceder a la élite en el poder.

La formación de estas facciones se debe a dos cosas: "primero, el individuo necesita al grupo para avanzar en su carrera $[\ldots] \mathrm{y}$,

22 Joy Langston, "Sobrevivir y prosperar: una búsqueda de las causas de las facciones políticas intrarrégimen en México", Política y Gobierno (México, Centro de Investigación y Docencia Económicas), vol. 2, núm. 2, 1995, p. 244. 
segundo, los incentivos electorales (o su carencia) aumentan la competencia dentro del régimen, controlada por los grupos y sus líderes". ${ }^{23}$ Estos dos aspectos se combinan cuando los líderes de las facciones usan éstas como un "banco de personal" para colocar a los individuos de confianza en los puestos públicos.

Estas facciones funcionan de manera clientelar, ya que el arreglo que hay entre el líder y un miembro de la facción es de superior-subordinado. Al unirse, el individuo disminuye los "costos de la búsqueda de un empleo al entregar sus responsabilidades a otro que es mejor para echársela a cuestas". ${ }^{24}$ Sin embargo, el subordinado no se confía, ya que de manera paralela construye o se integra a otra red, la cual puede ser ajena o formar parte de la misma facción. Ésta está integrada por amigos, colegas y asociaciones, quienes fungirán como protectores por si el líder de la facción falla en conseguirle un cargo en el sector público. La protección consiste en otorgarle otro puesto aun cuando éste no sea el deseable por el individuo. "Este tipo de cargos [los dados por la red] pueden no ser tan buenos como los que probablemente le otorgaría el grupo primario, pero funcionan como salas de espera hasta que surja algo mejor". 25

Finalmente, utilizaré a Panebianco, quien no define explícitamente el término facción, pero hace uso del análisis organizacional de los partidos políticos. Para entender su idea de facción es necesario retomar el concepto coalición dominante, el cual usa para definir a la élite dirigente de los partidos.

El concepto de coalición dominante, más amplio que aquellos que se usan generalmente, permite fotografiar mejor la efectiva estructura del poder en los partidos, ya sea cuando ésta implica la existencia de una alianza "transversal" (entre algunos líderes nacionales y algunos líderes locales), ya sea cuando implica, por el contrario, la alianza entre algunos líderes nacionales y algunos líderes de organizaciones formalmente externas y separadas del partido [...] la coalición dominante

${ }^{23}$ Ibid. p. 249.

24 Ibid. p. 257.

${ }^{25}$ Loc. cit. 
de un partido está integrada por aquellos actores, pertenezcan o no formalmente a la organización, que controlan las zonas de incertidumbre más vitales. ${ }^{26}$

Por zonas de incertidumbre, el autor entiende los "factores cuyo control permite a ciertos actores desequilibrar en su favor los juegos de poder". ${ }^{27}$ Estas zonas son: la de competencia, gestión de relaciones con el entorno, comunicaciones internas, reglas formales, financiamiento y reclutamiento.

Establece tres características de las coaliciones dominantes: 1) cuando sólo hay un líder del partido, éste tiene que negociar con otros actores organizativos; "en realidad él es el centro de organización de fuerzas internas del partido, con las que debe, al menos en cierta medida, avenirse a pactos". ${ }^{28}$ 2) El poder de organización del partido no está concentrado en los cargos internos o parlamentarios del mismo, sino también por sectores como sindicatos. 3) La coalición no implica que de ella sólo formen parte los líderes nacionales del partido, es decir, ésta comprende tanto a los "nacionales (o a un sector de ellos) como a un cierto número de líderes intermedios y/o locales". ${ }^{29}$

$\mathrm{El}$ autor indica que entre los actores organizativos se establece un proceso de negociación y reconoce que hay dos tipos: los "verticales", los cuales se presentan entre los líderes con los miembros de las bases de la organización; y los "horizontales", entre "los líderes de la coalición dominante, y entre la coalición dominante y las élites minoritarias". ${ }^{30}$ Además, agrega que ambos tipos de negociación son desequilibrados: "no son algo que tenga lugar únicamente entre la coalición dominante y sus seguidores, sino también en el propio seno de aquélla". ${ }^{31}$

La fisonomía de una coalición dominante es lo que distingue la estructura organizativa de un partido de la de otro. Ésta se examina

\footnotetext{
${ }^{26}$ Angelo Panebianco, op. cit., p. 91.

27 Ibid., p. 83.

${ }^{28}$ Ibid., p. 90.

${ }^{29}$ Loc. cit.

${ }^{30}$ Ibid., p. 91.

${ }^{31}$ Loc. cit.
} 
desde tres puntos de vista: grado de cohesión interna, grado de estabilidad y el mapa de poder que da lugar en la organización. He aquí donde aparecen las facciones de los partidos políticos.

La distinción del grado de cohesión se establece:

entre partidos subdivididos en facciones (es decir, grupos fuertemente organizados) o en tendencias (grupos débilmente organizados). Las facciones pueden ser de dos tipos: grupos que suponen un corte vertical del partido entero, desde el vértice hasta la base o bien grupos geográficamente concentrados, organizados sólo en la periferia del partido [...] Las tendencias se caracterizan por ser agrupaciones en el vértice, carentes de bases organizadas (lo que no significa, necesariamente, que carezcan de apoyos) en el conjunto de la organización. ${ }^{32}$

Como se puede observar, Panebianco utiliza la definición de facción de Richard Rose y afirma que cuando en un partido hay facciones, la coalición dominante se hallará poco cohesionada, "puesto que es el resultado de un compromiso entre diversas facciones -cada una de ellas con su propia individualidad-frente a otras". ${ }^{33}$ En cambio, en un partido político con tendencias, el control sobre las zonas de incertidumbre estará menos concentrado, y la coalición estará más unida.

Por lo anterior, es importante observar si la coalición está integrada por grupos y de qué tipo son: facciones o tendencias. Como se puede observar, lo que distingue a una u otra es el nivel de organización que tienen. Panebianco deja entrever que a mayor grado de organización de tales grupos, menor el grado de institucionalización y viceversa. Además, establece que:

[si se hace un] examen de los grupos, ya sean facciones o tendencias, descubriremos que ellos también son, en la mayoría de los casos, el resultado de alianzas entre grupos más pequeños. La diferencia está en que, si el grupo es una tendencia, los lazos entre los subgrupos son bastante más débiles y fluidos que los que aglutinan a los subgrupos

32 Ibid., p. 92.

33 Ibid., p. 93. 
que integran una facción. Lo importante en cualquier caso es que siempre la coalición dominante es una alianza de alianzas, una alianza entre grupos, que a su vez son coaliciones de grupos más pequeños. ${ }^{34}$

En segundo lugar, el grado de estabilidad "se refiere a los intercambios horizontales (entre élites), y en particular al carácter estable o precario de los compromisos en el vértice de la organización". ${ }^{35}$ Panebianco manifiesta que, por lo general, las coaliciones son estables. Sin embargo, no hay estabilidad si hay divisiones entre la coalición. Ella sólo puede mantenerse mediante compromisos aceptables entre las facciones que la integran.

Finalmente, por mapa de poder se entiende a las relaciones "entre las distintas áreas organizativas del partido (por ejemplo, el que se dé un predominio del grupo parlamentario, o de los dirigentes nacionales de la organización o de los dirigentes de la periferia, etc.), como las relaciones (de predominio, subordinación o cooperación) entre el partido y otras organizaciones". ${ }^{36}$

En el presente artículo entenderé las corrientes políticas o facciones como un grupo de individuos organizados (Langstone), con cierta cohesión y disciplina (Richard Rose), que se unen con la finalidad de perseguir una serie de metas comunes e individuales (Langstone). Estas corrientes están integradas por líderes y seguidores (Nicholas); los primeros con evidente liderazgo, con visión sobre los objetivos que debe perseguir el grupo, con mayor compromiso con la organización y con una relación diádica asimétrica con los seguidores; en cambio, éstos se comprometen con los líderes a estar en la mayor cantidad de actividades políticas que haga el grupo. Cada facción se distingue por tener ciertas actitudes y valores compartidos, ya que se desprenden de una ideología propia y bien definida, para poder diferenciarse entre los demás grupos (Richard Rose).

La función de las facciones consiste en obtener la mayor cantidad de ventajas de poder posibles (Beller y Belloni), las cuales

\footnotetext{
${ }^{34}$ Loc. cit.

${ }^{35}$ Loc. cit.

${ }^{36}$ Ibid., p. 94.
} 
pueden traducirse en obtención de cargos partidistas o públicos (Key), así como en la aplicación de políticas públicas o programas de gobierno que éstas impulsen. Sin embargo, estas ventajas las obtienen mediante distintos mecanismos entre el líder y el subordinado o mediante la negociación entre los distintos liderazgos de las facciones.

En el PRD este tema no es sencillo debido a que las organizaciones, como en todos los partidos políticos, siempre están cambiando. En las facciones sucede lo mismo, ya que algunos de los integrantes empezaron en una corriente y posteriormente cambiaron a otra. Esto ha provocado que la relación de poder entre ellas también se modifique, ya que en ciertos momentos cada corriente puede ser más fuerte o más débil.

En el partido en cuestión, las facciones son más identificables que en otros partidos, ya que las normas que rigen el partido las reconocen formalmente, lo cual las hace más visibles. Los miembros deben registrar sus corrientes ante ciertas instancias de la organización, deben entregar informes trimestrales, presentarse a los foros que organice el partido, tener una página electrónica, entre otras.

Las principales corrientes dentro del partido son Izquierda Democrática Nacional (IDN), Nueva Izquierda (NI) y Foro Nuevo Sol (FNS). Posteriormente surgieron otras por la ruptura de éstas o por nuevas alianzas entre los integrantes del partido. En esta situación se encuentran Unidad y Renovación (UNyR), antes Izquierda Democrática en Avance (IDEA); Izquierda Social (IS); Izquierda Unida (IU), la cual no fungió como una corriente, sino como un frente de facciones que apoyó a Alejandro Encinas para presidente del PRD en 2008, donde algunos de sus integrantes formarían la Red Nacional por la Unidad de las Izquierdas (RUNI); y, finalmente, Izquierda Renovadora en Movimiento (IRM), la cual estuvo auspiciada por Marcelo Ebrard.

De acuerdo con el libro Fisiones y fusiones del PRD, divorcios y reconciliaciones: La dirigencia del Partido de la Revolución Democrática 1989-2004, Víctor Hugo Martínez González plantea que las corrientes surgieron, en sus inicios, como grupos que disputaron los espacios de decisión partidista ante la figura de Cuauhtémoc 
Cárdenas. Él plantea que, desde la elección de Porfirio Muñoz Ledo como presidente nacional del partido, en 1993, comenzaron a congregarse grupos u organizaciones, a construirse alianzas, a establecerse frentes o a crearse corrientes para disputar espacios en los órganos del PRD.

A partir de la lucha por los cargos partidistas dentro del Comité Ejecutivo Nacional (CEN) del PRD se crearon ciertos grupos. En la disputa por la presidencia en 1993 de este órgano hubo cuatro frentes o corrientes: 1) Arcoiris, que apoyaba a Muñoz Ledo y se formó por exmiembros de la Corriente Democrática del PRI (CD-PRI), excomunistas, exmiembros del Partido Socialista de los Trabajadores (PST), de la Organización Revolucionaria Punto Crítico (ORPC), del Partido Revolucionario de los Trabajadores (PRT), de la Asamblea de Barrios y del Movimiento de Acción Popular. 2) Trisecta o Convergencia Democrática, cuyo candidato era Mario Saucedo. Esta corriente se integró por exmiembros de la Asociación Cívica Nacional Revolucionaria (ACNR), el Partido Popular Revolucionario (PPR), del Movimiento Revolucionario del Pueblo (MRP), de la Organización de Izquierda Revolucionaria (OIR), de la Unión Revolucionaria (UR), de la Corriente Izquierda Democrática (CID), de la Coalición Obrero Campesino Estudiantil del Itsmo (COceI), del Partido del Frente Cardenista de Reconstrucción Nacional (PFCRN) y de la CD-PRI. 3) Corriente Cambio Democrático, liderada por Heberto Castillo Martínez y donde hubo exmiembros del Partido Mexicano de los Trabajadores (PMT), de la CD-PRI y del Partido Comunista Mexicano (РСм). 4) Finalmente, el grupo de los excomunistas, quienes apoyaban a Pablo Gómez Álvarez. Posteriormente, estos grupos se dividieron y reacomodaron para la lucha por la siguiente dirigencia del cen en 1996, la cual ganó Andrés Manuel López Obrador (AMLO).

Del grupo Arcoíris surgieron, entre otros, los Peces, quienes eran un "conjunto de dirigentes del ex-PCM: Amalia García, Alejandro Encinas, Gilberto Rincón Gallardo, Raymundo Cárdenas, Martha Delia Gástelum y Hortensia Aragón. En 1999 crearían la 
corriente 'Amalios' o 'Foro Nuevo Sol'."37 Un segundo grupo fue el de "Los Chuchos", que se llamó así por:

sus dirigentes, Jesús Ortega y Jesús Zambrano, quienes tras coincidir en una fracción dentro del Partido Mexicano Socialista (PMS) [...] fundan la corriente "Nueva Izquierda". Promotora de una izquierda socialdemócrata, al nacer tuvo como miembros a los compañeros de sus líderes: Pedro Etienne, Angélica de la Peña y Carlos Navarrete (exmiembros del PST) y Rosario Tapia (exmiembro del Partido Popular Revolucionario). Dirigentes del PRD en el D.F. como Víctor Hugo Círigo y René Arce fueron también parte de sus primeros cuadros, lo mismo que individuos sin militancia previa como Lorena Villavicencio, Jorge Calderón y Ernesto Navarro. ${ }^{38}$

Además de estos dos grupos surgieron otros: Nueva República, liderados por Porfirio Muñoz Ledo y el Movimiento de Bases Insurgentes (MBI), donde destacan Raúl Álvarez Garín, Javier González, Asa Cristina Laurell y Marco Rascón.

La CID sustentó a la Trisecta; la primera empezó "su despunte en 1993 con la llegada de René Bejarano al PRD-DF. En 1994, Dolores Padierna coordinó a los asambleístas en el Distrito Federal. En 1996, la CID repetiría al frente del PRD capitalino con Armando Quintero. En 1997, Martí Batres ocuparía la coordinación legislativa en la ALDF". ${ }^{39}$ Otros simpatizantes de esta corriente son María Rosa Márquez (exmiembro del Partido Revolucionario Socialista) y Miroslava García (exmiembro del Consejo Estudiantil Universitario). De la CID salieron Armando Quintero para formar la corriente Izquierda Democrática en Avance (IDEA) y Rosario Robles, que organizó la alianza "A Pleno Sol” para impulsar a Carlos Ímaz para presidente del PRD-DF. "Estas dos [últimas] serían parte del grupo Regeneración, creado en 2001 para reivindicar el liderazgo de Cuauhtémoc Cárdenas e impulsar en 2002 la candidatura de Rosario Robles al CEN" ${ }^{40}$

37 Víctor Hugo Martínez González, Fisiones y fusiones. La dirigencia del Partido de la Revolución Democrática (PRD) 1989-2004, México, unam-Plaza y Valdés, p. 123.

38 Ibid., p. 123.

${ }^{39}$ Ibid., p. 123.

40 Ibid., p. 125. 
Después del 2002 se forjó otra corriente con integrantes de Regeneración y de la llamada Megacorriente, la cual presidió Rosario Robles. A principio de febrero de 2004 IDEA desapareció. Días después, ésta fue sustituida por la corriente Unidad y Renovación (UNyR), en la cual destacaron Rosario Robles, Ramón Sosamontes, Pablo Gómez, Gilberto Ensástiga, entre otros. ${ }^{41}$ Un mes después Televisa presentó una serie de videos en los cuales mostraban a personajes del Gobierno del Distrito Federal (GDF) involucrados en presuntos actos de corrupción, después llamados "videoescándalos". Esto provocó que esta corriente sufriera recomposiciones, ya que los dos primeros personajes estuvieron involucrados en los videos mostrados por la televisora.

Este escándalo causó también fracturas dentro de la corriente Izquierda Democrática Nacional (IDN). René Bejarano, principal líder de esta facción fue encarcelado y enseguida surgió la disputa por el mando de esta corriente. Estos hechos provocaron el desprendimiento de algunos miembros en 2006. De este rompimiento surgió Izquierda Social (Is); entre sus representantes se encontraba Martí Batres como líder, Alejandra Barrales, Javier Hidalgo, Elí Evangelista, Víctor Manzanares, Alfredo Hernández Raigosa, Dione Anguiano, Benito Mirón Lince, Francisco Chiguil, Uriel González, Faustino Soto, entre otros. ${ }^{42}$

En noviembre de 2006 se creó el Frente Político de Izquierda (FPI) como "contrapeso a la corriente Nueva Izquierda", ya que ésta pretendía deslindarse de las acciones de Andrés Manuel López Obrador. Este Frente estaría conformado por ocho corrientes distintas entre las que destacan Foro Nuevo Sol; Alternativa Democrática Nacional (ADN), que dirige Héctor Bautista; IDN; Is; Movimiento de Bases Insurgentes (мві), de donde fue miembro Gerardo Fernández Noroña; Red de Izquierda Revolucionaria (REDIR), encabezada por Camilo Valenzuela; unyr; y el Movimiento Nacional Organizado Aquí Estamos. ${ }^{43}$

${ }^{41}$ La Jornada, 21 de febrero de 2004.

42 La Jornada, 1 de octubre de 2006.

${ }^{43}$ La Jornada, 10 de noviembre de 2006. 


\section{Cuadro 1}

Evolución de las corrientes más importantes que están presentes en el Distrito Federal

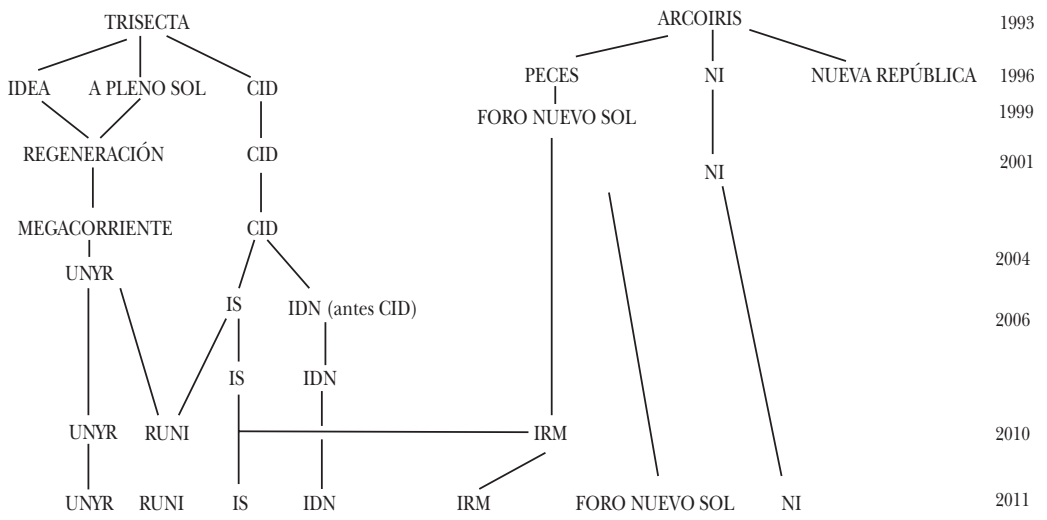

Fuente: Elaboración propia con base en información hemerográfica y Víctor Hugo Martínez González, Fisiones y fusiones. La dirigencia del Partido de la Revolución Democrática (PRD) 1989-2004, México, unAm-Plaza y Valdés.

En septiembre de 2007, Alejandro Encinas convocó a la formación de la alianza Izquierda Unida (IU), cuyo principal objetivo era ganar la presidencia nacional del PRD en 2008. Este frente estuvo formado por cinco corrientes: Foro Nuevo Sol, Is, IDN, UNyR e Izquierda en Movimiento. ${ }^{44}$

Después de que Alejandro Encinas y Jesús Ortega disputaron la Presidencia del CEN del PRD, se creó, en febrero de 2010, la Red por la Unidad Nacional de las Izquierdas (RUNI), a la cual pertenecieron Alejandra Barrales, Pablo Gómez, Alfonso Ramírez Cuellar, Gilberto y Erasto Ensástiga, entre otros. ${ }^{45} \mathrm{Al}$ mismo tiempo y como contrapeso, UnyR e Is formaron un frente para discutir, según Armando Quintero, "temas que inquietan a la población". ${ }^{46}$

Por último, nació Izquierda Renovadora en Movimiento (IRM). Su coordinador fue Miguel Moreno Brizuela, quien ocupó la Secretaría

${ }^{44}$ La Jornada, 23 de septiembre de 2007.

${ }^{45}$ La Jornada, 1 de febrero de 2010.

${ }^{46}$ La Jornada, 8 de febrero de 2010. 
de Protección Civil del GDF durante la gestión de Marcelo Ebrard. Otros integrantes de la corriente fueron Martha Delia Gastélum, José Antonio Rueda, José Ángel Ávila Pérez, Jesús Valencia, entre otros. ${ }^{47}$ En el cuadro 1 se ha mostrado la evolución de las facciones del PRD en la Ciudad de México:

COALICIÓN DOMINANTE EN LAS DIRIGENCIAS ESTATALES DEL

Distrito Federal

Panebianco reflexiona acerca de dos posturas sobre la distribución de poder en las organizaciones:

Los que consideran válida la "ley de hierro", aducen habitualmente como prueba el fenómeno de la larga permanencia de ciertos líderes al frente de muchos partidos, su capacidad de manipular los congresos nacionales y otras instancias partidarias mediante técnicas plebiscitarias, etc. Por el contrario, los que niegan la validez se amparan en general tras el argumento de que, en una asociación voluntaria, los líderes deben tener en cuenta necesariamente la voluntad de sus seguidores, y aducen que, lo que se observa en la mayoría de los casos es un acuerdo sustancial entre unos y otros sobre la política a seguir. ${ }^{48}$

Sin embargo, arguye que dichas posturas parten sobre dos definiciones de poder distintas: una como propiedad y la otra como una relación de influencia. Para ello Panebianco define al poder como: "un tipo de relación, asimétrica, pero recíproca, que se manifiesta en una 'negociación desequilibrada', en un intercambio desigual en el que un actor gana más que el otro. Al ser una relación de intercambio, o mejor, manifestándose de esa forma, el poder no es nunca absoluto, sus límites están implícitos en la misma naturaleza de la interacción". ${ }^{49}$ Él mismo afirma que la definición no es suficiente y que es necesario observar "qué se cambia, cuáles

${ }^{47}$ El Universal, 15 de agosto de 2010.

${ }^{48}$ Angelo Panebianco, op. cit., p. 62.

${ }^{49}$ Ibid., p. 64. 
son, por así decir, los 'objetivos que pasan de mano en mano en las 'negociaciones desequilibradas'”. ${ }^{50}$

Este autor destaca que para observar aquello que se intercambia se deben distinguir dos tipos de negociación: entre líderes (horizontales) y entre líderes y seguidores (verticales). Entre mayor poder y margen de maniobra tengan los líderes a partir de los juegos verticales, más serán los recursos de los mismos en los juegos horizontales. "En otros términos, cuanto mayor sea la libertad de acción de los líderes, éstos se hallarán en mejores condiciones para resistir el asalto de los adversarios internos". ${ }^{51}$ En este caso, la variable dependiente son los juegos horizontales y la independiente son los verticales. De acuerdo a Panebianco, "los juegos de poder verticales, son la precondición, por lo menos lógica, de los juegos de poder horizontales, y que los resultados de las negociaciones entre los líderes dependen de los resultados de las negociaciones entre líderes y seguidores". 52

Por ello, es necesario revisar los juegos de poderes horizontales expresados en la conformación del Comité Ejecutivo Estatal (CEE) en la Ciudad de México, desde la elección de la primera, presidido por Heberto Castillo, hasta la encabezada por Manuel Oropeza. Para ello, nombraré a los personajes y corrientes que ganaron de manera directa la presidencia. Por falta de espacio no abarcaré el análisis de otros espacios importantes dentro del cEe como la Secretaría General o la de Organización, la Electoral o la de Finanzas, las cuales se consideran estratégicas.

En los juegos horizontales o entre corrientes se establece el proceso de negociación para la distribución y asignación de las distintas secretarías del CEE. Anteriormente, los estatutos indicaban que las secretarías deberían repartirse proporcionalmente a las planillas ${ }^{53}$ según el número de votos de cada una. El único capital

${ }^{50}$ Ibid., p. 65.

51 Ibid., p. 66.

52 Ibid., p. 67.

${ }^{53}$ Las planillas se forman por los miembros del partido para contender en las elecciones internas del mismo. Los representantes de cada una de ellas entregan la lista de los integrantes que las componen, en las que el primero en lista contiende por la presidencia, el segundo por la secretaría general y los siguientes por las consejerías, ya sean estatales o nacionales. 
político que tenían las corrientes para negociar espacios en el CEE era el porcentaje de votación obtenido en la elección de presidente, secretario general y consejeros. El proceso de negociación se establecía entre los líderes de cada corriente y no había necesidad de que los acuerdos fueran ratificados por algún órgano partidista.

A partir de diciembre de 2009, mes en que se modificaron los estatutos, la propuesta de presidente debe ser ratificada por mayoría calificada por el Consejo Estatal, lo cual formará alianzas o acuerdos entre las corrientes que integran este órgano. Podría suceder que la corriente con la primera minoría en el Consejo sólo necesitara de otra con poca representación (tercera o cuarta fuerza). En ese caso, no se tomaría en cuenta a las restantes, incluso la segunda fuerza, para ratificar la propuesta del presidente para integrar el CEE. Lo anterior tendría como consecuencia que la cantidad de miembros por planilla en la integración del Comité no necesariamente sea proporcional a los votos obtenidos por cada una. En cualquiera de los dos casos, proporcional o no proporcional, la negociación es indispensable para la repartición de cargos.

De esta manera, la coalición dominante del PRD en el Distrito Federal se conforma con la asignación de cargos partidistas a cada corriente. Esta coalición sólo forma parte de una coalición nacional, la cual no necesariamente tiene la misma correlación de fuerzas que la primera.

La corriente más importante hasta el 2012 fue IDN (antes de 2006 denominada CID), la cual ha competido en todas las elecciones internas. Posteriormente, de ella surgieron idea (en el año 2004 se convierte en UNyR) e Is; ambas se crearon justo cuando sus líderes, impulsados por IDN, ocupaban la presidencia del Comité Ejecutivo Estatal. Los dos principales cargos del cEe, Presidencia y Secretaría General, han sido ocupados por estas corrientes y por Nueva Izquierda, la cual se formó en 1996, aunque sus adherentes en la capital ya participaban en las elecciones internas abanderados por la Corriente por la Reforma Democrática.

Durante el periodo de estudio la coalición dominante estuvo integrada por cuatro corrientes: IDN, NI, UNyR e IS. Estas corrientes conformaron una coalición, pero cada una de ellas controló ciertas zonas de incertidumbre tal como lo define Panebianco. Las 
corrientes que no formaron parte de esta coalición son Foro Nuevo Sol, ADN, REDIR O MBI, por mencionar algunas.

Desde 1990 hasta el año 2010 hubo doce presidentes del PRD en el Distrito Federal y dos presidencias colegiadas, las cuales se han distribuido en siete comités ejecutivos estatales. En el cuadro 2 se nombran los presidentes del CEE-DF y la corriente de la que provienen.

Por estatutos, la planilla que haya ocupado el segundo lugar obtendrá la Secretaría General, a menos que la ganadora haya obtenido más de $50 \%$ de la votación. La única ocasión que sucedió esto fue cuando ganaron Martí Batres (IDN hasta ese momento) y Gilberto Ensástiga (UNyR), ya que ambos compitieron bajo una sola planilla aun siendo de distintas corrientes. En las demás ocasiones, la Secretaría General fue ocupada por los segundos lugares.

Como se puede ver en el mismo cuadro 2, IDN ha ganado tres presidencias; IDEA, Nueva Izquierda e Izquierda Social sólo una vez. Sin embargo, en dos de las tres presidencias de IDN, los presidentes Armando Quintero y Martí Batres aprovecharon su posición para crear su propia corriente política. En las presidencias interinas, IDN ha ocupado este puesto en dos ocasiones; las demás por otras corrientes o personas que no participan con ninguna como Ricardo Ruiz.

La conformación de cada Comité ha dependido no sólo de las corrientes políticas que han competido por la presidencia, sino del contexto en el que se presentan las elecciones de las dirigencias. Las tres primeras fueron electas cuando el PRD era oposición en el gobierno local; las siguientes cuando el partido ganó el GDF.

Desde que Carlos Ímaz fue electo presidente del partido, siempre han existido acusaciones acerca de la intervención del Gobierno de la Ciudad de México en las elecciones internas. La elección de Ímaz fue producto, acusaron miembros de IDN, de la decisión de Rosario Robles, entonces secretaria de Gobierno, de apoyarlo. ${ }^{54}$ Antes de ser presidente, Ímaz fungió como Director de Participación Ciudadana del GDF, lo cual pudo haberle valido el apoyo de Robles, ya que se denunció que en dicha dirección se creó una estructura de ciudadanos, paralela a la de las corrientes, la cual fue movilizada a favor de Ímaz.

${ }^{54}$ Reforma, 13 de septiembre de 2008. 


\section{Cuadro 2}

\section{Presidentes del Comité Ejecutivo Estatal de la Ciudad de México}

\begin{tabular}{|c|c|c|}
\hline $\begin{array}{l}\text { Comité Ejecutivo } \\
\text { Estatal }\end{array}$ & Nombre (s) del Presidente & Corriente \\
\hline \multirow[t]{2}{*}{ I } & Heberto Castillo 1990 & - \\
\hline & Marco Rascón 1991 & - \\
\hline \multirow[t]{11}{*}{ II } & René Bejarano 1994 & IDN \\
\hline & Primera Presidencia colegiada (julio 1995): & Corriente por la Reforma \\
\hline & Gonzalo Rojas & Democrática \\
\hline & David Cervantes & IDN \\
\hline & Ernesto Jiménez & Grupo Jampel \\
\hline & Segunda Presidencia colegiada (julio 1995): & Representante del CEN \\
\hline & Javier González Garza & Corriente por la Reforma \\
\hline & René Arce & Democrática \\
\hline & Armando Quintero & IDN \\
\hline & Javier Hidalgo & $\begin{array}{c}\text { Asamblea de Barrios (no } \\
\text { corriente) }\end{array}$ \\
\hline & $\begin{array}{l}\text { Dirigencia acéfala. Se hace cargo de la } \\
\text { dirección el cEN (abril 1996) }\end{array}$ & \\
\hline III & Armando Quintero (junio 1996) & $\begin{array}{l}\text { Llegó por IDN, pero } \\
\text { durante su presidencia } \\
\text { creó IDEA }\end{array}$ \\
\hline \multirow[t]{2}{*}{ IV } & Carlos Ímaz (mayo 1999) & Apoyado por IDEA \\
\hline & Porfirio Martínez (enero 2002) & Convergencia Alternativa \\
\hline \multirow[t]{2}{*}{$\mathrm{V}$} & Víctor Hugo Círigo (mayo 2002) & NI \\
\hline & Agustín Guerrero (febrero 2003) & IDN \\
\hline \multirow[t]{2}{*}{ VI } & Martí Batres (mayo 2005) & $\begin{array}{l}\text { Llegó por IDN, pero } \\
\text { durante su presidencia } \\
\text { creó Is }\end{array}$ \\
\hline & Ricardo Ruíz (diciembre 2006) & Sin corriente \\
\hline \multirow[t]{2}{*}{ VII } & María Alejandra Barrales (octubre 2008) & Is y luego se unió a RUNI \\
\hline & Manuel Oropeza (octubre 2009) & IDN \\
\hline
\end{tabular}

Fuente: Elaboración propia con información del Instituto Electoral del Distrito Federal y hemerográfica. 
A partir de esa elección, la disputa por la presidencia del PRD en la Ciudad de México ha desembocado en conflictos postelectorales (a excepción del 2005). Incluso, en la elección en que participaron Víctor Hugo Círigo y Agustín Guerrero se acusó al primero de recibir recursos del gobierno delegacional de Iztapalapa. ${ }^{55}$ IDN y Agustín Guerrero trataron de anular la elección ${ }^{56}$ y acudieron al Instituto Federal Electoral a "interponer un recurso de derechos ciudadanos y políticos, a fin de que el IFE verifique si la elección perredista del 17 de marzo [de 2002] estuvo apegada a la normatividad de este partido". ${ }^{57}$ En 2008, Jesús Zambrano, de Nueva Izquierda, acusó a Alejandra Barrales, de Izquierda Social, de violar los topes de campaña y solicitó la anulación de la elección ante la Comisión Nacional de Garantías ${ }^{58}$ y, posteriormente, ante el Tribunal Electoral del Poder Judicial de la Federación.

A pesar de los conflictos que presentaron, las corrientes en disputa siempre establecieron acuerdos. Las disputas poselectorales se han resuelto mediante la negociación de las Secretarías de Organización, Finanzas y Acción Electoral del CEE, por ser las tres carteras más disputadas. En ellas se tiene control de zonas de incertidumbre para manejar recursos y hacerse de otros. La importancia de estas tres secretarías se reflejó en la primera Presidencia Colegiada, ya que éstas también se estructuraron igual con representantes de cada corriente. Las tres secretarías mencionadas arriba se han repartido entre IDN y NI. Sin embargo, desde que IDEA surgió en 1999, también ha ocupado la de Organización y Finanzas. En cambio Is, que ganó la presidencia en 2008, no ha tenido la misma suerte.

La coalición dominante es una construcción precaria, sensible a choques externos "cuando demuestra no estar ya en condiciones de controlar las zonas de incertidumbre organizativa; o bien puede disolverse a causa de sus conflictos internos, debido a cambios en el centro de gravedad del poder" ${ }^{59}$ En este caso, la coalición en el

\footnotetext{
55 Reforma, 12 de marzo de 2002.

${ }^{56}$ Reforma, 29 de abril de 2002.

${ }_{57}$ Reforma, 4 de mayo de 2002.

58 Reforma, 16 de abril de 2008.

${ }^{59}$ Angelo Panebianco, op. cit., p. 92.
} 
PRD-DF se mantuvo a pesar de los conflictos que se presentaron en la elección de sus dirigentes.

Respecto al grado de cohesión interna, los cargos partidistas han sido ocupados por las corrientes IDN, NI y UNyR (antes IDEA). Las zonas de incertidumbre han estado repartidas entre las corrientes, las cuales son usadas para obtener ventajas ante las demás. Este comportamiento muestra una coalición dominante poco cohesionada.

Este factor no inhibe que haya cierto grado de estabilidad en los acuerdos y respeto entre las corrientes, pues saben que gozan de recursos que las otras no, pero también, que les faltan otros que las demás tienen. Es decir, saben que la cooperación es indispensable y que la necesidad de establecer acuerdos siempre será superior a las diferencias. Hasta el momento se presentaron rompimientos, pero ninguno que hubiera segregado a alguna corriente en la representación del cEE. Un ejemplo claro es el desprendimiento de UNyR e Is de IDN; a pesar de ello, las tres mantuvieron comunicación y establecieron acuerdos.

\section{LAS FACCIONES EN LOS GABINETES, EN LA ALDF Y EN LAS DELEGACIONES}

Las corrientes del PRD en la capital del país no sólo han contendido por los espacios clave dentro del CEE; también lo han hecho por tener la mayor cantidad de Consejeros Estatales y Congresistas. Estos cargos son necesarios para decidir el método de elección de candidatos para jefe de gobierno, diputados locales y jefes delegacionales. Los espacios dentro del partido que tiene cada corriente representan sólo un peldaño para hacerse de otros, entre los que se encuentran los puestos de representación popular (diputados y jefaturas delegacionales) y cargos públicos de la administración del Gobierno del Distrito Federal.

A excepción de 2003, desde 1994 los consejos estatales han decidido que los candidatos a los distintos puestos de representación popular sean elegidos mediante elección abierta a los afiliados. Ésta puede ser directa o indirecta. En la primera, los afiliados 
eligen de manera directa a los candidatos a diputados uninominales, a la jefatura de gobierno y a las delegacionales; en la segunda, se eligen a convencionistas, quienes son los encargados de negociar y elegir a los candidatos. En ambos métodos, el papel que representan las corrientes es clave, ya que las facciones deben persuadir a los afiliados para que sufraguen por los candidatos de su respectiva corriente o para elegir a los convencionistas, quienes representan a las corrientes que habrán de decidir quiénes serán los candidatos.

En 1997 la votación fue directa para elegir candidatos a diputaciones locales y a jefe de gobierno; en 2000, indirecta para elegir candidatos a diputados locales y directa para jefe de gobierno y mixta para jefes delegacionales; ${ }^{60}$ en 2003, mediante encuestas (método al cual se opusieron algunos líderes); finalmente, en 2006 y 2009 por elección directa.

\section{Gabinetes DEL JEFE DE GObieRno}

Las corrientes, especialmente IDN, han apoyado a los últimos cuatro jefes de gobierno electos. Cuando el primero ganó la Jefatura de Gobierno, Armando Quintero afirmó que habría que reestructurar el CEE debido a que entre sus integrantes había próximos diputados locales y manifestó que "habrá que agregar los que sean llamados por el Jefe de Gobierno electo a algún cargo público". ${ }^{61}$ Es decir, ya se esperaba un pago de cuotas (patronazgo) por el apoyo en la elección. Por ejemplo, René Bejarano no pudo ser diputado local por vía plurinominal debido a la alta votación que tuvo el PRD en 1997; sin embargo, Cárdenas le asignó la Dirección General de Gobierno, la cual depende de la Secretaría de Gobierno.

Durante la campaña de López Obrador a jefe de gobierno, dos líderes de las tres principales corrientes en la ciudad lo apoyaron: René Bejarano de IDN y Armando Quintero de la entonces recién

${ }^{60}$ Reforma, 27 de febrero de 2000.

${ }^{61}$ Reforma, 22 de julio de 1997. 
creada IDEA (después UNyR). ${ }^{62} \mathrm{El}$ primero fungió como responsable de giras y eventos de la campaña; el segundo, en mantener las relaciones con organizaciones sindicales y agrupaciones políticas locales. ${ }^{63}$ Ya en la Jefatura de Gobierno, Bejarano fue el secretario particular de AMLo hasta 2002 cuando renunció para buscar la diputación local. Quintero fue diputado local (de representación proporcional) de 2000 a 2003 y jefe delegacional de Iztacalco de 2003 a 2006.

Otros integrantes de IDN ocuparon cargos públicos en el Gobierno del Distrito Federal, pero no en el gabinete; algunos de ellos son: Ángeles Correa, como Director de Justicia Cívica de la Consejería Jurídica; Rosa Icela Rodríguez, Directora General de Concertación Política de la Secretaría de Gobierno; y Manuel Oropeza, Director de Análisis Político. Sin embargo, ningún miembro de estas corrientes ocupó alguna secretaría.

En 2005, IDN y unyr también apoyaron la candidatura de Marcelo Ebrard a jefe de gobierno; Batres de is lo apoyó cuando fue presidente del PRD, lo cual le valió que las demás corrientes solicitaran su renuncia. Los líderes de las dos últimas corrientes ocuparon espacios en el gabinete del jefe de gobierno: Martí Batres como secretario de Desarrollo Social y Armando Quintero como secretario de Transporte y Vialidad. Incluso, Foro Nuevo Sol tuvo un cargo público: subsecretario de Gobierno a cargo de Juan José García.

\section{ALDF}

Actualmente los distritos para elegir diputados locales son más competidos por los precandidatos. Antes de 1997, los espacios de representación de la ciudad no eran tan disputados como ahora. La expectativa por la copiosa votación que tuvo el PRD instigó mayor jaloneo por esos espacios.

En la elección para diputados para la I Legislatura de la ALDF (1997-2000), las corrientes se pusieron de acuerdo para tener 32

${ }^{62}$ Reforma, 18 de octubre de 1999.

${ }^{63}$ Reforma, 20 de febrero de 2000. 
candidaturas de unidad en 40 espacios uninominales. ${ }^{64}$ Sin embargo, a partir del año 2000 el forcejeo aumentó, principalmente por la presencia de tres corrientes políticas y porque tenían una gran expectativa respecto a la participación ciudadana, dado que en 1997 se ganaron 38 diputaciones locales y la Jefatura de Gobierno.

A partir de 2003 estuvieron en juego intensas negociaciones entre las corrientes para determinar quiénes serían los candidatos a diputados. La II Legislatura (2000-2003) tuvo 19 diputaciones para el PRD; en la tercera (2003-2006), 37; la cuarta (2006-2009), 33; la quinta (2009-2012) y sexta (2012-2015), 34 en cada una.

De igual manera que los espacios en el CEE, las corrientes han estado presentes en la ALDF. En la I Legislatura convivieron miembros de IDN (13 diputados ${ }^{65}$ ), de Asamblea de Barrios (4), de Corriente por la Reforma Democrática (8) y del grupo Jampel (2). En la segunda también estaría presente IDN (10) junto con el llamado Grupo de los 3 (Horacio Martínez, Ruth Zavaleta y Edith Santacruz Fabila) y el Grupo de los 6 (con miembros de lo que sería Unyr). En la tercera legislatura hubo miembros de IDN (19), NI (5) y unyR (7); en la cuarta, IDN (10), NI (16) y unyr (2); esta fue la única vez que la corriente dominante, IDN, no obtuvo la mayoría. La quinta estuvo marcada por la conformación de la alianza llamada Izquierda Unida, la cual estaba integrada por IDN (11), Is (3), UNyr (4) y Foro Nuevo Sol (1). Sin embargo, en diciembre de 2009 se desprendieron miembros de las dos últimas para crear RUNI (5), liderada por Alejandra Barrales. ${ }^{66}$ Además, Nueva Izquierda también estuvo presente en la quinta Legislatura con 8 diputaciones.

En la VI Legislatura de 2012 a 2015, IDN (12), Unyr (1), Is (1), NI (8), RUNI (2) y ADN (1). Algunos de los diputados restantes fueron personas allegadas al grupo de Marcelo Ebrard, incluso al

${ }^{64}$ Reforma, 13 de febrero de 1997.

65 El número que está escrito entre paréntesis responde a los diputados que pertenecían a cada corriente durante la legislatura, los cuales pudieron haber pertenecido a una corriente distinta antes de ocupar una curul o cambiado a otra posteriormente. La información se basa en una revisión hemerográfica. Sin embargo, no obtuve la información completa de todos los integrantes de cada una de las legislaturas de la ALDF.

${ }^{66}$ La Jornada, 14 de diciembre de 2009. 
actual Jefe de Gobierno. Tal es el caso de Manuel Granados Covarrubias, quien fue líder coordinador del PRD y presidente de la Comisión de Gobierno de la ALDF, otrora asesor de Miguel Ángel Mancera en la Procuraduría General de Justicia del Distrito Federal. El mapa de corrientes en la actual Legislatura ha cambiado, ya que no sólo conviven tres corrientes, sino seis, así como miembros cercanos al actual y anterior Jefe de Gobierno.

El hecho de que las corrientes puedan ocupar espacios dentro de la ALDF muestra dos cosas: 1) la fortaleza que tienen éstas en los órganos de decisión para postular candidatos al poder legislativo local; y 2) la práctica del patronazgo que sirve para colocar a las personas más allegadas a los líderes de las facciones, incluso, si se postulan a dichos puestos por vía uninominal o por representación proporcional.

En algunos casos, los conflictos entre corrientes han sobrepasado los órganos partidistas y han suscitado problemas dentro de la ALDF por razones ajenas a la actividad legislativa. Por ejemplo, en 2002, debido al conflicto poselectoral por la presidencia del PRDDF, los representantes de IDN y NI se dividieron en la Asamblea. Los primeros decidieron desconocer al nuevo presidente del PRD-DF, ya que éste pertenecía a Nueva Izquierda. ${ }^{67}$ Finalmente, esto se resolvió cuando las corrientes negociaron y decidieron realizar cambios en la ALDF y redistribuyeron las presidencias de algunas comisiones, así como de la Mesa Directiva. Lo anterior, a cambio de que se reconociera la nueva dirigencia del PRD en la Ciudad de México. ${ }^{6}$

\section{Delegaciones Políticas}

En la Reforma Política que se ejecutó en el otrora Distrito Federal durante 1997, se contempló que los primeros delegados serían nombrados por una terna que el Jefe de Gobierno mandaría a la ALDF para que ésta decidiera. Cárdenas no nombró a líderes sobresalientes de las corrientes que había en el momento. Esta decisión

${ }^{67}$ Reforma, 24 de mayo de 2002.

${ }^{68}$ Reforma, 11 de septiembre de 2002. 
fue una recomendación de Francisco Garduño, colaborador del exjefe de gobierno, quien incluso entregó una propuesta de los requisitos que deberían tener los Delegados, entre los que destaca "contar con una amplia trayectoria política, una destacada experiencia profesional, y un conocimiento preciso de la problemática de cada demarcación, además de que deben haber residido en la zona por lo menos tres años para que sean propuestos". ${ }^{69}$ Esto fue una estrategia para evitar ser rehén de las corrientes que apoyaron la campaña de Cárdenas. Ante tal recomendación, Armando Quintero solicitó a los Comités Delegacionales proponer a los delegados nombres de personas para ocupar "puestos operativos, debajo de los delegados y subdelegados", ${ }^{70}$ es decir, hubo presión para que las corrientes ocuparan puestos de la administración pública.

En el año 2000, por primera vez hubo elecciones populares para jefe delegacional. La elección de los candidatos del PRD a las delegaciones fue por dos métodos distintos para diferentes delegaciones. Por un lado, el Consejo Estatal eligió cinco candidatos (Azcapotzalco, BenitoJuárez, Iztacalco, Gustavo A. Madero y Tlalpan); $;^{71}$ por otro lado, en las delegaciones restantes los candidatos fueron elegidos directamente por los militantes.

Tres años después, en 2003, la decisión para las candidaturas a jefe delegacional se hizo mediante encuestas. "En los listados se incluyeron, en primer término, a un representante de las principales corrientes internas de ese partido y en segunda instancia a líderes sociales de cada demarcación."72 Como no se incluyeron a todos aquellos que querían contender por tal, entonces exigieron que se hiciera una elección, hecho que no ocurrió. ${ }^{73}$ En 2006 y 2009, el Consejo Estatal decidió que la elección de candidatos a jefes delegacionales fuera abierta a la militancia.

Así como en 1997, en 2000 fueron pocos los candidatos a jefe delegacional que pertenecían a alguna corriente. Esto se observa

${ }^{69}$ Reforma, 23 de noviembre de 1997.

70 Reforma, 12 de diciembre de 1997.

${ }^{71}$ Reforma 24 de marzo de 2000.

72 Reforma 23 de enero de 2003.

${ }^{73}$ Reforma 31 de enero y 4 de febrero de 2003. 
con Dolores Padierna de IDN como candidata y, posteriormente como jefe delegacional en Cuauhtémoc y René Arce Islas de Ni en Iztapalapa. También Guadalupe Chavira de IDN en Milpa Alta y Gilberto López y Rivas de IDEA (después unyR) en Tlalpan.

Posteriormente, la presencia de las corrientes en las delegaciones fue más numerosa. En 2003, IDN tuvo ocho delegaciones; Nueva Izquierda, dos (Iztapalapa y Venustiano Carranza); e IDEA (Unyr), dos (Iztacalco y Tlalpan). En 2006, IDN sólo obtuvo seis; NI consiguió tres y Unyr aumentó a cuatro, arrebatando a IDN las delegaciones de Magdalena Contreras y Tláhuac. En 2009 IDN disminuyó a cinco; NI mantuvo sólo Venustiano Carranza y Milpa Alta; unyr sólo Iztacalco, Magdalena Contreras y Tláhuac; Izquierda Social ganó Gustavo A. Madero, sin embargo, Víctor Hugo Lobo, actual jefe delegacional, cambió de corriente en diciembre de 2009 a RUNI; finalmente Coyoacán e Iztapalapa: en la primera Raúl Flores, identificado con Alejandro Encinas, recibió apoyo de IDN; la segunda fue un caso excepcional dado que todas las corrientes, excepto NI, apoyaron a Clara Brugada.

En 2012 IDN obtuvo seis delegaciones (Álvaro Obregón, Azcapotzalco, Cuauhtémoc, Magdalena Contreras, Tlalpan y Xochimilco), una más a comparación de 2009; Ni aumentó dos más, ya que además de haber tenido Venustiano Carranza y Milpa Alta, obtuvo Gustavo A. Madero y Coyoacán; Unyr y RUNi han mantenido una cada una, Iztacalco y Tláhuac respectivamente; el grupo de Marcelo Ebrard ganó en Iztapalapa con Jesús Valencia; y Foro Nuevo Sol obtuvo Miguel Hidalgo, la cual ganó por primera vez el PRD con Víctor Hugo Romo.

Con la información anterior parecería que las corrientes tuvieron un control territorial muy definido. Hasta 2012 se identifican claramente cuáles fueron los bastiones de cada una de las distintas corrientes en la capital. Aun cuando hay miembros de distintas corrientes que predominan en cada uno de los 40 distritos locales y las 16 delegaciones, la corriente dominante en una delegación puede no serlo en algún distrito que la conforma. 


\section{CONCLUSiones}

De acuerdo a la evidencia empírica concluyo que efectivamente, como lo planteé en la hipótesis, las corrientes políticas del PRD en la ciudad están organizadas en grupos que pretenden mantenerse en los cargos partidistas, en los públicos y en los puestos de representación popular para lo cual utilizan mecanismos de patronazgo.

Cada facción ha buscado hacerse de más elementos para aumentar sus recursos humanos, materiales y económicos. Cuando las corrientes obtienen y amplían éstos, entonces compiten con las otras facciones existentes en los juegos horizontales. Ellas luchan en distintos canales: en los mediáticos tratando de crear cierta imagen; con los ciudadanos para engrosar las filas de cada corriente ya sea persuadiendo o restándole clientes a alguna corriente adversa; y en los canales institucionales dentro del partido, donde compiten por obtener las candidaturas a puestos de representación popular. Esta competencia implica la negociación entre las distintas facciones, su medición de fuerzas (tamaño de la red clientelar, la capacidad de movilización de ciudadanos a distintos eventos políticos, la garantía de obtener votos en un territorio determinado) y el reconocimiento de cuáles corrientes controlan qué zonas de incertidumbre y cómo éstas pueden ampliarse o reducirse para alguna corriente durante un nuevo proceso de negociación.

Por ejemplo, antes de negociar cómo se seleccionará a los candidatos de representación popular (votación por consejo, candidatura única o votación universal), las corrientes del PRD saben que tienen que hacerse de los cargos partidistas para controlar ciertas zonas. Por eso, no es casual que las secretarías del Comité Ejecutivo Estatal más competidas son Organización, Finanzas y Acción Electoral, ya que éstas, junto a la Presidencia y la Secretaría General, tienen control sobre las "zonas de incertidumbre vitales para la organización”.

Aquellas facciones que participan en el control del PRD en la capital también son quienes obtienen candidaturas a los puestos de representación popular e influencia para proponer integrantes a los cargos públicos que se desprenden de la administración pública local, ya sea en el Gobierno del Distrito Federal o en las delegaciones. 
El conjunto de estas corrientes conforma la coalición dominante. En ella participan IDN, NI, Is, UNyR y posteriormente se han integrado Foro Nuevo Sol, IRM, RUNI y ADN, aunque con menor fuerza.

Como se observó, durante el periodo de estudio, IDN ha controlado más espacios en el CEE, en la ALDF y delegaciones políticas; NI aparece en segundo lugar con menos espacios; posteriormente se encuentran unyr e Is, las cuales son corrientes con menor antigüedad que las anteriores y que además ambas se desprendieron de IDN; Foro Nuevo Sol, corriente con mayor antigüedad, aparece marginalmente en la ALDF y en el GDF; por último, las corrientes de más reciente creación, IRM y RUNI, ligadas a Marcelo Ebrard, aparecen cuando éste llega a la jefatura de gobierno.

Las corrientes tienen representación en los órganos del PRD, en la ALDF, en el GDF y en las delegaciones políticas; entonces cada facción se allega de más recursos para seguir reproduciéndose y mantener los cargos ya ganados.

No hay duda de que los juegos verticales son precondición de los horizontales tal como lo afirma Panebianco. Sin embargo, estos últimos también fortalecen a los primeros. Inicialmente, para que las corrientes mantengan su nivel de fuerza se ven obligados a nutrir ininterrumpidamente los verticales por lo que necesitan constantemente de recursos. Entre más fortaleza tengan las corrientes en los juegos horizontales más probabilidad tendrán de ganar y mantener los puestos de representación popular y los cargos públicos. Ya establecidos éstos, los miembros de las corrientes tienen más recursos para fortalecer los juegos verticales. De esta manera se establece un ciclo entre ambos juegos, el cual crece y se fortalece.

La segunda conclusión en términos organizativos refiere que el PRD nació de la unión de varios partidos políticos y organizaciones sociales. Sin embargo, con el paso del tiempo han sido las corrientes políticas las que han sido parte estructural en la vida del partido. Esto no significa que no haya habido personajes ajenos a ellas y que aún los haya. Incluso, personalidades como Cuauhtémoc Cárdenas, Andrés Manuel López Obrador, Alejandro Encinas, por mencionar algunos, no han tenido afiliación en alguna corriente. Pero el hecho de que no estén afiliados no significa que no las utilicen y que en algunos casos dependan de ellas. 
Las corrientes son una herramienta necesaria. La necesidad de ellas para ciertos actores políticos es tanta porque no hay forma de competir contra ellas y de conseguir recursos de una manera rápida y eficaz. Los actores que dependen de las corrientes saben que éstas representan un compromiso muy fuerte, pero también reconocen que no pueden despreciarlas o ser indiferentes ante ellas. Si quieren seguir siendo personajes importantes dentro del PRD tienen que negociar con ellas.

Los órganos institucionales del PRD podrían existir sin las corrientes; incluso podrían derogar los artículos que permiten la existencia de las mismas. Sin embargo, esto no va suceder por dos hechos: 1) el Congreso y el Consejo Nacional están conformados, en su mayoría, por las distintas facciones partidistas; y 2) las corrientes no van a inmolarse por el "bien" del partido debido a que ha sido por medio de éste que han ganado poder, el cual se refleja con recursos económicos y políticos. Por esta razón, la pelea por los espacios más importantes del partido como la presidencia y la secretaría general sólo se da entre las corrientes más fuertes.

Indudablemente hay actores dentro del partido interesados en restar poder a las corrientes. Sin embargo, ni Cuauhtémoc Cárdenas, López Obrador o Marcelo Ebrard pudieron hacerlo cuando fueron jefes de gobierno. No obstante, con la administración de Miguel Ángel Mancera, éste decidió dejar fuera de su gabinete a miembros de las corrientes del PRD. La única cartera importante en el Gobierno del Distrito Federal fue para IDN con la Secretaría de Desarrollo Rural, la cual ocupó Hegel Cortés Miranda hasta mediados de 2015.

Aunado a lo anterior, durante la presente administración esta misma corriente tuvo cargos públicos menores, aunque nada despreciables, como la Dirección General Registro Civil o la Dirección General para el Fondo para el Desarrollo Social. El subsecretario de Gobierno, Juan José García Ochoa, pertenece a la corriente Foro Nuevo Sol y ha permanecido en el cargo desde la gestión de Marcelo Ebrard. De igual manera, en lo extenso de la administración pública del Distrito Federal también hay cargos de muy bajo perfil que son ocupados por miembros de diversas facciones. 
La ausencia de las diversas corrientes en el primer nivel del Gobierno del Distrito Federal ha provocado que algunas de éstas hayan sido muy críticas con el jefe de gobierno. Por un lado, esto ha provocado una disminución en la movilización de simpatizantes, dinero o apoyos materiales para las facciones del partido. Por otro lado, el actual jefe de gobierno no ha podido incidir en la vida partidista tanto como sus antecesores en razón del rechazo a estas facciones. Es de entender que éste no tiene los recursos necesarios, ni la relevancia suficiente en el partido para incidir plenamente en la vida partidista.

Por último, el gran cisma que sufrió el PRD a nivel nacional después de la elección de 2012, del cual surgió el partido político Movimiento de Regeneración Nacional (Morena), ha modificado la dinámica del sistema de partidos dentro de la capital desde 2015. Lo anterior ha establecido una nueva correlación de fuerzas dentro del órgano legislativo.

Después de algunas semanas en que los diputados locales ocuparan sus cargos como diputados, Morena se convirtió en la fracción parlamentaria con la primera minoría con 20 diputados y el PRD en segunda con 17. No obstante, Morena no ha hecho valer su fuerza para ocupar los cargos más importantes dentro de la ALDF, ya que no obtuvieron ni la presidencia de la Comisión de Gobierno ni otras importantes como la de Presupuesto. De igual manera, tampoco obtuvo la Oficialía Mayor de la Asamblea, a cargo de Guillermo Sánchez, miembro de la corriente IDN y ya antes diputado local y federal, así como exjefe delegacional en Tlalpan. En cambio, el PRD, como segunda fuerza política, ha hecho las alianzas necesarias junto con las subsiguientes fracciones parlamentarias para mantener éstos y otros espacios dentro de la ALDF.

En el caso de las delegaciones, Morena obtuvo Azcapotzalco, Cuauhtémoc y Tláhuac, Xochimilco y Tlalpan. Por un lado, las últimas tres ubicadas al sur destacan por tener una importante zona rural. Cabe destacar que el territorio de la Ciudad de México contiene $60 \%$ suelo rural y $40 \%$ urbano. Sin duda, estas tres delegaciones representan una importante extensión del territorio de la ciudad, sin olvidar que Tlalpan es la más grande de todas las demarcaciones territoriales. Por otro lado, la delegación Cuauhtémoc es 
una de las delegaciones más importantes por estar en la zona céntrica de la capital, donde se ubican las colonias más añejas de la ciudad, donde están las sedes del Poder Judicial, Poder Ejecutivo y la Cámara de Senadores y, por ende, donde se desarrolla el intercambio político de orden nacional. Además de ello, en esta zona del país es donde se produce una gran actividad económica y financiera dentro el país.

Ricardo Monreal, jefe delegacional en Cuauhtémoc, ha sido el más cooperativo con el Gobierno del Distrito Federal. En el caso de las delegaciones del sur, sí ha habido cooperación, aunque en menor medida. En cambio, con Azcapotzalco ha sido muy menor el contacto.

Después de seis meses de estar en la vida institucional, Morena no ha tenido una importante relevancia dentro del juego legislativo. En un primer momento esto se ha interpretado como una falta de oficio por parte de su coordinador parlamentario para construir acuerdos y alianzas. Sin embargo, esto también puede ser una estrategia a mediano plazo, con la finalidad de ganar la siguiente elección en 2018, cuando se contienda no sólo por diputaciones locales, jefaturas delegaciones y la Jefatura de Gobierno, sin olvidar los cambios que alentará la nueva Constitución de la Ciudad de México para la elección de alcaldías y concejales en cada una de éstas.

En resumen, paralelamente existe un juego cooperativo entre las delegaciones y el Gobierno del Distrito Federal, y otro de confrontación constante entre la fracción parlamentaria de Morena con las demás fuerzas políticas y algunas dependencias del gobierno de la capital. Por ello, cabe preguntarse también si hay distintas visiones y grupos dentro de Morena. Mediáticamente, los principales líderes de este partido han declarado que son un único partido.

Ante este contexto de Morena, vale recordar una reflexión que hacía Heberto Castillo en noviembre de 1991 sobre los comités estatales del PRD:

sufren la amenaza de que las organizaciones que actúan como fracciones se apoderen de sus direcciones, siguiendo el método de la penetración sistemática, aplastando a los grupos menores y conduciendo al PRD al debilitamiento o división interna [donde los grupos] tienen 
habilidad para la transacción, para la negociación de posiciones y para el cultivo de los dirigentes. El afán de lograr la dirección hace que rechacen a quienes llegan al partido sin más aportación que su capacidad individual, y muchos valiosos compañeros han abandonado nuestras filas o se han sumado a ellas conscientes de que no pueden vencer la barrera de esos sectarismos.

\section{Bibliografía}

Belloni, Frank P. y Dennis C. Beller, "Party and Faction: Modes of Political Competition", en Dennis C. Beller y Frank P. Belloni, Faction Politics: Political Parties and Factionalism in Comparative Perspective, Oxford, ABC-Clio, 1978.

—, "The Study of Party Factions as Competitive Political Organizations", The Western Political Quaterly (University of Utah), vol. 9, núm. 4, 1996.

Bruhn, Kathleen, Taking on Goliath: The Emergence of a New Left Party and the Struggle for Democracy in Mexico, Filadelfia, Pennsylvania University Press, 1997.

Langston, Joy, "Sobrevivir y prosperar: una búsqueda de las causas de las facciones políticas intrarrégimen en México", Política y Gobierno (México, Centro de Investigación y Docencia Económica), vol. II, núm. 2, 1995.

Martínez González, Víctor Hugo, Fisiones y fusiones. La dirigencia del Partido de la Revolución Democrática (PRD) 1989-2004, México, unAM-Plaza y Valdés.

Michels, Robert, Los partidos políticos. Un estudio sociológico de las tendencias oligárquicas de la democracia moderna, Buenos Aires, Amorrotou, 1969.

Ortega Ortiz, Reynaldo Yunuen, "El proceso de democratización en México, 1968-2002”, en Walther L. Bernecker (comp.), Transición democrática y anomia social en perspectiva comparada, México, El Colegio de México, 2004.

, "El Partido de la Revolución Democrática y los movimientos sociales", en Ilán Bizberg y Francisco Zapata (coords.), Los grandes problemas de México, Volumen VI, Movimientos sociales, México, El Colegio de México, 2010. 
Panebianco, Angelo, Modelos de partido, trad. de Mario Trinidad, Madrid, Alianza, 1990.

Prud'homme, Jean-Francois, "El PRD: su vida interna y sus elecciones estratégicas", México, cide, Documento de Trabajo de la División de Estudios Políticos, núm. 39, 1996.

Reveles Vázquez, Francisco (coord.), Partido de la Revolución Democrática. Los signos de la institucionalización, México, unam-Gernika, 2004.

Rose, Richard, "Parties, Factions and Tendencies in Britain", Political Studies (Washington, D. C., American Political Science Association), vol. 12, núm. 1, 1964.

Stokes, Susan C., "Political Clientelism", en Robert E. Goodin, Carles Boix, Susan C. Stokes, The Oxford Handbook of Comparative Politics, Oxford, Oxford University Press, 2007.

Documentos del Partido de la Revolución Democrática

Estatutos del Partido de la Revolución Democrática, 1990

Estatutos del Partido de la Revolución Democrática, IV Congreso

Estatutos del Partido de la Revolución Democrática, VI Congreso

Estatutos del Partido de la Revolución Democrática, VIII Congreso

Estatutos del Partido de la Revolución Democrática, XI Congreso

Estatutos del Partido de la Revolución Democrática, XII Congreso

Reglamento de las Corrientes de Opinión

Reglamento General de Elecciones y Consultas

Reglamento del a Comisión Nacional de Garantías

Periódicos de 1993 al 2011

El Universal

La Jornada

Reforma

Página electrónica

Asamblea Legislativa del Distrito Federal

Atlas Socioeconómico y de Marginación para el DF de la Coordinación 
de Planeación del Desarrollo Territorial, http://www.siege.df.gob. $\mathrm{mx} /$ copladet/index.html

Comunicado Número 091/10 del Instituto Nacional de Estadística y Geografía (INEGI), http://www.inegi.gob.mx/inegi/contenidos/espanol/ prensa/Boletines/Boletin/Comunicados/Especiales/2010/Marzo/ comunica9.pdf

Cámara de Diputados, Perfil socioeconómico del Distrito Federal, junio de 2009, http:/ / www.cefp.gob.mx/intr/edocumentos/pdf/cefp/200 9/cefp0372009.pdf

Partido de la Revolución Democrática

Partido de la Revolución Democrática en el Distrito Federal

Programa de Naciones Unidas para el Desarrollo, Índice de Desarrollo Humano Municipal en México, 2004, http://www.undp.org.mx/desarrollohumano/eventos/images/CuadernilloIDHMM.pdf 